\title{
Understanding leisure satisfaction of Chinese seniors: human capital, family capital, and community capital
}

Chenchen Huang ${ }^{1 *}$ and Ying $\mathrm{Li}^{2}$

* Correspondence: huangc@
buffalostate.edu
'Hospitality and Tourism
Department, State University of
New York- Buffalo State, Buffalo, NY
14222, USA
Full list of author information is
available at the end of the article

available at the end of the article

\begin{abstract}
This study investigates the impacts of human capital, family capital, and community capital on Chinese seniors' leisure satisfaction. One thousand seniors living in five Chinese cities participated in this quantitative study. The findings suggest a significant impact from family capital, while the impacts of human capital and community capital are mixed and inconsistent. A discussion of the findings and suggestions for practical implication are presented.
\end{abstract}

Keywords: Leisure satisfaction, Chinese seniors, Human capital, Family capital, Community capital

\section{Introduction}

In China, age 60, rather than 65 as in most developed countries, is used as a marker of old age. The 5-year difference implies that population aging is a relatively new phenomenon in China, compared with the Western world. The graying of Chinese society is a cumulative effect of a low fertility rate and rising life expectancy resulting from the implementation of one-child policy and its more recent economic takeoff since the late 1970s. China's life expectancy rose from 50 years old in 1950, to 73 years old in 2010, and is expected to rise to 80 years old in 2050 (National Bureau of Statistics of China 2013). The figure in metropolitan cities is even higher (e.g., life expectancy in Hangzhou, one of the survey sites for this study, reached 81 years old in 2010). While the population aging phenomenon is new, it is happening at an unprecedentedly rapid pace and the sheer size of the elderly population is enormous. China is already an aging society with $15.5 \%$ of population aged 60 and above in 2016 . By 2030 , the proportion of elderly population is estimated to increase to $25 \%$, or about 340 million. By 2050, China is predicted to have one-fourth of the world's $60+$ population, nearly 450 million, which will count for about $30 \%$ of its total population.

It is particularly important to note that the current legal retirement age in China is 60 for male workers and officials, 50 for female workers, and 55 for female officials (in certain professions with harsh working conditions, men can retire at 55 years old and women at 45 years old) (findlaw.cn 2014). With a life expectancy of 74.8 years, most Chinese elders will spend, on average, almost

(c) The Author(s). 2019 Open Access This article is distributed under the terms of the Creative Commons Attribution 4.0 International License (http://creativecommons.org/licenses/by/4.0/), which permits unrestricted use, distribution, and reproduction in any medium, provided you give appropriate credit to the original author(s) and the source, provide a link to the Creative Commons license, and indicate if changes were made. 
15 years in retirement. This number is significantly higher for those who are women and/or live in metropolitan cities.

Retirement can be challenging and sometimes even considered problematic for the wellbeing of the elderly. Renowned gerontologist Moody (2000) once said: "what is problematic about retirement is not that work is always better but that the abundance of free time in late life is not adequately structured for any larger social purpose or meaning" (p. 268). It is well established in the literature that leisure is central to later life wellbeing (e.g., Gibson and Singleton 2012). The concept of leisure referenced here is commonly defined as follows: (1) time free from the necessity to labor for a livelihood, such as work and daily chores; (2) activities that free one from his or her obligations; and (3) experience that is positive and pleasant in its participants' view (Hurd and Anderson 2010; Kelly, 2012).

While the definition of leisure being leisure time, leisure activities, and a subjective experience has been adopted and adapted into research studies on leisure in China, there is no consensus on how Chinese culture shapes the understanding of leisure in the Chinese context. Dong and Chick (2012) find in their empirical study that time and money are the biggest constraints to leisure participation perceived by Chinese people, same as reported in western societies. Based on their survey of over 900 Chinese seniors, Li et al. (2017) report that leisure is understood as to relax ( $84 \%$ of the respondents), to do things that make oneself happy (83\%), to kill free time (53\%), to do job-unrelated things (34\%), and to do nothing (20\%). Most of the ideas are generally consistent with the definitions of leisure by Hurd and Anderson (2010), and Kelly (2012). There are, however, some evidence that the Chinese interpret the subjective leisure experience differently. For example, some Chinese people do not view perceived freedom as central to their leisure experience (Walker and Wang 2009).

A brief survey of literature published in Chinese on elder leisure indicates that most empirical studies focus on leisure behaviors, and the space and temporal distribution of leisure behaviors (e.g., Sun 2000; Sun et al. 2001). These studies provide a foundation for understanding leisure behaviors and for making public policies to provide leisure opportunities for elders in China. Nevertheless, there is a scarcity of studies on leisure satisfaction of elders in China.

The existing body of literature on the elderly population in China, mostly accumulated in the past 10-15 years, is fragmented to some extent. In particular, the focus of previous studies is considerably lopsided. The distinctive culture of filial piety in China emphasizing adult children's obligations for elder care and the effects of the more recent one-child policy on family structure have drawn most of the attention of scholars in this field. Elder care (financial care and/or physical care) provided by family has been the central focus of studies on later-life wellbeing, including leisure satisfaction. Essentially, family has been the main, if not the only, focus of aging studies in China. As a result, the roles of self and community have been largely ignored.

The current research focuses on leisure satisfaction of Chinese seniors, a largely uncharted area of study. We examine direct and indirect indicators of social advantages and disadvantages in shaping later life quality in leisure satisfaction. While recognizing the important role of family and family capital, we are also interested 
in investigating the roles of self (human capital) and community (community capital). Specifically, we investigate the impacts of human capital, family capital, and community capital on leisure satisfaction of Chinese seniors.

\section{Literature review}

\section{Leisure satisfaction and human capital}

Two dimensions of human capital are investigated in this research: demographic characteristics and physical health. Demographic variables indicate individuals' leisure preferences, interests, abilities, and resources. Research studies investigating the connection between demographic characteristics and leisure satisfaction have long been reported in the literature. Individuals with different demographic backgrounds have sometimes shown different leisure preferences and experienced different levels of leisure satisfaction. For example, Son et al. (2008) find that age and gender variables affect constraint negotiations in physically active leisure. Li et al. (2017) report that various demographic variables affect how Chinese seniors perceive different leisure constraints.

Leisure research often includes demographic variables in the analysis as control variables, as well as the main variables under investigation. As control variables, demographic variables help researchers discern different cohorts and explore alternative explanations. When studied as the main variables, demographic variables have provided ample opportunities for research inquiries for the last few decades. Some of the main findings can be read in works such as Floyd et al. (2008) on race and ethnicity, and Freysinger et al. (2013) on gender issues.

The literature is generally inconsistent and inconclusive with regard to the connection between demographic variables and leisure participation and satisfaction of Chinese seniors. Demographic variables often interact with each other and make the efforts of deciphering their impacts on leisure more complicated (e.g., Tsai 2006). In addition to the complexity of the relationship itself, empirical research studies in the English literature are often based on samples of overseas Chinese seniors living outside of China and are often dated, with most studies conducted at least 10 years ago. There are, however, a few exceptions where empirical studies on leisure activities of elders in China are reported in the Chinese literature. For example, Sun et al. (2001) report some connections between gender, age, and income and leisure time and leisure activities among elders living in Beijing, China.

After a brief summary of the literature as follows, it is clear that a re-examination of the relationship between these demographic variables and contemporary Chinese seniors is warranted. Research on leisure satisfaction in older age cohorts is especially intriguing because work roles for seniors have largely been relinquished. Consequently, leisure plays a bigger and more important role in the lives of seniors. Clearly, then, age can be related to leisure satisfaction even in later stages of life. Gender seems not to play a significant role in leisure participation and leisure satisfaction among overseas Chinese in Australia (Tsai and Coleman 1999), in the USA (Li and Stodolska 2006), and in Canada (Spiers and Walker 2008). However, in a study of Chinese residents in Macao, China, Ngai (2005) uncovers that men expressed greater levels of leisure satisfaction than women. In a large-scale cross-sectional survey of over 2000 older adults living in Hong Kong, Chou et al. (2004) find that gender and level of education attainment correlate with participation in leisure activities, although there is no consistent pattern. 
According to China National Nutrition and Health Survey cited by Bauman et al. (2010), Chinese with higher educational attainment are more likely to engage in leisure-time physical activities. Similarly, Yu et al. (2000) find that educational attainment is inversely associated with lack of leisure-time physical activities among Chinese seniors. Unlike findings in American studies such as Satariano et al. (2002), Chou et al. (2004) find no connection between income/financial situation and participation in leisure activities among Chinese older adults in Hong Kong. Chou et al. (2004) report that marital status is related to participation in one out of seven categories of leisure activities by Chinese elderly in Hong Kong. Tsai's (2006) in-depth interviews with Taiwanese women find that being married limits and constrains interviewees' participation in leisure activities.

In addition to these demographic characteristics, physical health is likely affecting leisure satisfaction of seniors. The literature has long established the relationship between health and leisure (e.g., Coleman and Iso-Ahola 1993). Payne et al. (2006) find evidence to support the argument that leisure activities help the health of older adults. Chick et al.s (2014) study reports a strong connection between leisure satisfaction and self-reported health after surveying over 700 individuals in 6 big cities in China. For the elderly, the connection could be even stronger. Good physical health not only enables seniors to enjoy leisure activities but also frees up financial resources and time for leisure participation (e.g., Rosenberger et al. 2005).

Hypothesis 1: human capital has significant positive effects on leisure satisfaction of Chinese seniors.

\section{Leisure satisfaction and family capital}

Family capital can be viewed as a form of social capital (Bubolz 2001). Social capital represents a resource that exists between individuals. Family capital represents the social resource among family members. Positive family capital embodies the principles of reciprocity and exchange. For example, older adults can draw support from their adult children, and grandparents are often able to take care of grandchildren. The size of family networks often varies, but family functioning in a family of any size can be similar if positive family capital is present. Bengtson and Roberts (1991) operationalize family capital as intergenerational solidarity-intergenerational cohesion between parents and their adult children.

Family, rather than individuals, is often the organizing unit of various leisure pursuits for older adults. Leisure participation is an important part of the family function. Stalker (2011) argues that a huge amount of family capital is spent on work- and family-related responsibilities, and consequently a lack of remaining family capital is a significant constraint of leisure. From a leisure-constraints perspective, this lack of ample family capital is a deterrent to leisure participation and leisure satisfaction. For example, a lack of family support, being restricted by family, and being busy with housework are among the constraints identified by Dong and Chick (2012) in their study of leisure constraints in six Chinese cities.

Although Western-based leisure studies rightfully emphasize the individual and internal benefits when analyzing leisure satisfaction (Chick et al. 2014), family leisure remains an important and fruitful stream of research (Hodge et al. 2015). Furthermore, 
family capital could be more important for Chinese seniors from a cultural standpoint. Leung et al. (2004 p. 187) find that in China "the elderly emphasized the relationship with family members and took the needs of the family as their personal needs." Spiers and Walker (2008) argue that in Confucian philosophy, family takes the center stage in everyday existence. Strong family ties and traditional Chinese values and beliefs play big roles in Chinese seniors' lives, including their leisure lives and leisure satisfaction.

Hypothesis 2: family capital has significant positive effects on leisure satisfaction of Chinese seniors.

\section{Leisure satisfaction and community capital}

Community capital is a form of social capital that represents the networks and linkages in the community (Kearns 2003). Both bonding social capital and bridging social capital vary at the community level (Flora 2004; Flora and Flora 2002). Bonding social capital refers to relationships that include elements such as mutual trust, reciprocity, and shared values. Bridging social capital exists when people reach out of their normal group to different groups of people. Varying community capital can be expressed through trust, social connections, social exchanges, and reciprocity within the community.

\section{Communities in big cities and in medium and small cities}

From the perspective of bonding social capital, the bigger the group is, the more difficult it is to have sufficient social relationship capital in the group (Hayami 2009). Big cities in China expand at a fast pace with more social mobility. As a result, connections and social exchanges between individuals can be different, and more challenging to create, than those in medium-size and small cities. Bridging community capital can help people connect across these larger communities and develop inter-community linkages. In short, a larger community might harbor or require greater bridging social capital. In China's big cities, efforts from local governments and new communication tools such as electronic social networks and personal communication applications might encourage and support social interactions between natural groups.

\section{Types of neighborhoods}

Broadly speaking, community can be defined as a body of relationships, rooted in a local place (e.g., neighborhoods) or shared meanings (which often transcend geographic proximity). For this particular project, we focus specifically on the local communities rooted in neighborhoods. This is largely because neighborhood is considered much more important in later life than in earlier years, as a result of shrinking social circle due to retirement and decreased mobility. Dayuan and shequ are two representatives of different types of communities in Chinese cities nowadays.

Up until the 1990s, most urban residents in China lived in so-called Dayuan, or Big Yard in verbatim English. These Dayuan neighborhoods are often a residential compound composed of residents who work for the same factory or government unit, and many are legacy from the urban work unit system-danwei, a key feature of the pre-reform era. From the 1950s to the late 1980s, during the era of the planned economy, urban China was defined by the danwei or the work unit system, geographically 
speaking as well as organizationally speaking. Everyone belonged to a danwei, which provided more than just employment but also cradle-to-grave welfare benefits as well as social identity. Colleagues were also neighbors living in the same danwei compound, aka the Dayuan, sharing an array of social services such as housing, healthcare, education, pension, and others.

However, from the late 1980s through the 1990s, many state-owned enterprises were bankrupt resulting in massive layoffs, which then led to the dismantling of most danwei, and the disintegration of the associated public service system. Meanwhile, a housing reform also took place in 1998, which abandoned the old system of linking housing distribution with employment and led to the later boom of the housing market. The commercialization of housing led to the rapid decline of Dayuan and gave birth to shequ, or neighborhoods in which residents from different backgrounds purchase their houses and become neighbors who share little in common. But these shequ neighborhoods might not be "communities" as defined by Western societies, which has a strong focus on grassroots efforts in its formation and evolvement. In 1994, the Ministry of Civil Affairs of China officially defined shequ as the lowest administrative unit. Community activities and programs in shequ are mostly initiated and managed by a semi-governmental and self-governing entity, Urban Residential Committee.

Though significant interests have been generated among scholars on the transformation of local communities from danwei to shequ and the emergence of community-based services from the more recent welfare reforms, virtually no empirical studies have explored the impact of these changes on the leisure life and wellbeing of the elderly population. They, as a cohort, witnessed and experienced a full range of China's massive transformations in their lifetime and continue to do so in their retirement. By doing a comparison between seniors living in Dayuan and in shequ, we hope to help fill the knowledge gap.

\section{Trust in China}

Trust is not only a basic human need but also the foundation of moral behavior-individuals can rely on others and trust them to do what is expected (Bubolz 2001). Trust supports the reciprocal relationship, and more social interactions and cooperation foster mutual trust (Hayami 2009).

Within the Chinese context, the importance of trust in the formation and accumulation of social capital is particularly salient. Despite the tumultuous changes in China's political and social landscape in the past century, Chinese people continue to hold and exhibit high generalized trust and a sensitivity of trust to social distance, according to (Buchan and Croson 2004; Newton 2001). In particular, Zhang and Zhang (2015) report high institutional trust among retirees in China.

As mentioned earlier, the dissolution of danwei and Dayuan, aggressive housing reform and other major construction projects, as well as widespread labor migration have reshaped not only the physical landscape but also the moral landscape, specifically greatly strained trust in urban China. Previously, residents of a Dayuan were usually colleagues who worked in the same work unit who engaged in a great deal of community capital development and maintenance featuring reciprocity and trust. Today's 
neighborhoods (shequ) tend to consist of residents who often share little in common. Popular media often portrays a so-called moral crisis in the ever-richer urban China and speaks of the danwei era in a nostalgic tone.

Aiming to evoke mutual help and trust among shequ neighbors, China's shequ development movement from the late 1990s heavily propagates the slogan of "establishing new types of neighborhood relationships"(建立新型邻里关系). One of the key targeted populations for this initiative is the elderly residents whose wellbeing is more likely to be impacted by their immediate neighborhood moral culture.

\section{Locals and migrants}

Recent waves of domestic migration in China have created a new social division between locals and migrants among seniors. The economic reform triggered a large-scale migration of young workers from rural areas to cities (Liu 2014). In the first decade of the twenty-first century, an average of 15 million rural-urban migrants per year moved to cities (Zhang 2001). In 2012, 230 million people were residing in places other than their hometowns, and $80 \%$ of them were rural-urban migrants (National Population and Family Planning Committee 2013).

The tradition of staying close to family has sparked the phenomenon of Chinese seniors moving to the cities where their adult children live. This movement can also be explained by cultural values and economic necessity. Many parents of those migrant workers decide to move to their adult children's cities after retirement or after a certain age, while some seniors remain in their own cities and become so-called" left-behind parents" (Huang et al. 2016). While some research studies have investigated the health and wellbeing of left-behind parents, little has been reported in the literature about the migrating seniors. Mao and Zhao (2012) report that migrating adolescents in Shanghai, China, have significantly fewer social connections, lower self-esteem, and higher levels of depression than their local peers. For seniors who migrate to their adult children's cities, the relocation may have similar impacts on them. The comparison between migrants and locals could shed some light on leisure satisfaction of Chinese seniors.

Hypothesis 3: community capital has significant positive effects on leisure satisfaction of Chinese seniors.

\section{Research design}

Measurement

The questions in the leisure section are adopted from the Taiwanese portion of the International Social Survey Programme (2007): Leisure Time and Sports Questionnaire. The ISSP is a continuing annual program of cross-national collaboration with more than 50 countries and regions administering surveys covering topics important for social science research. In 2007, the ISSP made the decision to have "leisure time and sports" as a new topic and spent 3 years of drafting and pre-testing within multiple countries and regions (International Social Survey Programme 2007). The questionnaire was originally drafted in English and then translated into Chinese using standard back-translation procedures.

Human capital is measured in two dimensions: demographic characteristics and self-reported health. Demographic variables measured in this study include age, gender, 
marital status, educational attainment, and income. The measurement of family capital is based on Bengtson and Roberts' (1991) theoretical model of intergenerational solidarity, which possesses six dimensions: structural, associational, consensual, affectual, functional, and normative. Please see the Appendix 1 for the questions used to measure family relationship. Results from these six dimensions are collapsed into a single measure of family relationship. In addition, whether or not the senior is living with family is also an indicator of family capital.

The measurement of community capital originates partially from the Integrated Questionnaire for the Measurement of Social Capital (SC-IQ) provided by the World Bank (2003). In particular, the trust dimension of the SC-IQ (please see the Appendix 1 for questions measuring trust) is adopted in this study and collapsed into one single measurement of trust of the community. The authors also conducted an in-depth interview with 18 Chinese elders in 2 cities to gain some insights to identify additional measurements that pertain to the Chinese context. Consequently, two additional variables are employed: residing in a Dayuan (as compared to shequ) and being a migrant (as compared to being a local). Leisure satisfaction is measured by a Likert-type question, with $1=$ extremely unsatisfied and $5=$ extremely satisfied.

\section{Data collection}

The participants were community-dwelling seniors in five cities-Hangzhou, Fuzhou, Nanchang, Leshan, and Suichang. These five cities were chosen as the research sites for two primary reasons. First, those five cities represent big, medium-size, and small cities in China. They locate in the eastern, middle, and western region in China. Second, the authors were able to secure local connections in those five cities so that local partners and interviewers were trained to collect the data. Please see Table 1 for more details about the five cities.

From February 2015 to May 2015, one of the authors spent her sabbatical leave in China to train local interviewers. The interviewers received training that helps them understand the research project, survey questions, human subject rights, and interview skills. In addition, ongoing consultation by the authors was provided when the interviewers had questions or needed support during the data collection period.

The survey was distributed to 1000 community-dwelling elders in those five cities from May 2015 to September 2016.The participants were approached in their living communities and were provided with a small gift of appreciation (worth about 5 yuan, equivalent to USD 0.7), such as a small hand towel after the survey was completed. Participants were also recommended through references and local connections. A quota

Table 1 Information on the survey sites

\begin{tabular}{lllllll}
\hline Name & Province & Region & Status & $\begin{array}{l}\text { Size } \\
\left(10,000 \mathrm{~km}^{2}\right)\end{array}$ & $\begin{array}{l}\text { Population } \\
\text { (millions) }\end{array}$ & $\begin{array}{l}\text { GDP per capita } \\
(1000 \mathrm{RMB})\end{array}$ \\
\hline Hangzhou & Zhejiang & East & Provincial capital & 1.66 & 754 & 132 \\
Fuzhou & Fujian & East & Provincial capital & 1.20 & 693 & 82 \\
Nanchang & Jiangxi & Middle & Provincial capital & 0.74 & 525 & 94 \\
Leshan & Sichuan & West & Regional city & 1.27 & 3.52 & 46 \\
Suichang & Zhejiang & East & Local city & 0.25 & 0.23 & 51 \\
\hline
\end{tabular}

Information quoted from China Statistical Yearbook 2017 by National Bureau of Statistics of China 
sampling was used to capture the gender ratio of the elderly population in each city. Each survey was completed through face-to-face interviews by Chinese-speaking interviewers at the interviewee's home or another place designated by the interviewee. Each survey question was read to the participants, and the answers were recorded by the interviewers. On average each interview lasted about $60 \mathrm{~min}$. If a participant opted to stop the interview before it was completed, the interviewer was instructed to stop and discard the incomplete interview. In total, 200 completed interviews were collected in each of the 5 cities.

\section{Results}

Demographic characteristics of the participants are summarized in Table 2. Table 3 presents the breakdown among subgroups of local participants and migrant participants, and participants living in Dayuan and in shequ.

The regression model is an ordinary least squares (OLS) regression model. The regression model takes leisure satisfaction as the dependent variable and various variables measuring human capital, family capital, and community capital as independent variables (Table 4). The $F$ value of the multiple regression model equals 12.75 with a significance level $p<0.01$, indicating the overall fitness of the model. The $\mathrm{R}$ square of this model is 0.20 .

\section{Results of hypotheses testing}

Some variables pertaining to human capital have significant impacts on leisure satisfaction. Hypothesis 1 is partially supported. Compared to single seniors or widows and

Table 2 Demographic profile of participants

\begin{tabular}{lll}
\hline Variable & Count & Percentage \\
\hline Sex & 534 & 54.9 \\
Female & 438 & 45.1 \\
Male & & 26.9 \\
Age & 258 & 37.3 \\
$55-64$ & 358 & 35.8 \\
$65-74$ & 344 & \\
75 and up & & 30.9 \\
Educational attainment & 301 & 22.9 \\
Elementary or lower & 223 & 21.1 \\
Middle school & 205 & 25.1 \\
High school & 244 & \\
College and higher & & 75.6 \\
Marital status & 720 & 24.4 \\
Married & 233 & 80.1 \\
Single/widowed/separated & & 7.9 \\
Income & 771 & 11.8 \\
Retirement pension & 77 & \\
Government aid & 114 & \\
Others & & \\
\hline
\end{tabular}


Table 3 Distribution of subgroups

\begin{tabular}{lll}
\hline Panel A: breakdown of local residents and migrants & & Total \\
Local residents & Migrants & 801 \\
492 & 309 & $100 \%$ \\
$61.4 \%$ & $38.6 \%$ & \\
Panel B: breakdown of Dayuan vs. Shequ & & Total \\
Dayuan & Shequ & 809 \\
356 & 453 & $100 \%$ \\
$44 \%$ & $56 \%$ & \\
\hline
\end{tabular}

widowers, married seniors have significantly higher levels of leisure satisfaction. Seniors who are at least 75 years old are more satisfied with their leisure experience than seniors who are younger than 75 years old. Seniors who report better physical health are more satisfied with their leisure experience. Educational attainment and gender do not have significant impacts on leisure satisfaction.

Family capital has a significant impact on leisure satisfaction. Hypothesis 2 is supported by the data. Chinese seniors who report closer and stronger family relationships are more satisfied with their leisure experience. Chinese seniors who live with their family are more satisfied with their leisure experience than those who live alone.

Some indicators of community capital have significant impacts on leisure satisfaction. Hypothesis 3 is partially supported. Chinese seniors' trust toward members of the community is an important predictor of their leisure satisfaction. The other three measurements of community capital, however, do not have significant impacts on leisure satisfaction of Chinese seniors. There is no significant difference between Chinese seniors who are migrants and those who are locals, between those who live in big cities and those who do not, and between those who live in Dayuan and those who live in shequ.

\section{Conclusion}

\section{Discussion}

In terms of human capital, having a spouse, being of an older age, and being in good physical health contribute to leisure satisfaction of Chinese seniors. Many studies (e.g., Waite and Gallagher 2002) support the idea that married people are happier. In our study, married seniors are more satisfied with their leisure lives. Married seniors could also have more support and resources in their leisure lives.

Older adults (75 years old and up) are more satisfied with their leisure lives than their younger counterparts. This interesting finding seems contradictory to the notion that older adults are more likely to be limited by deteriorating health, less discretionary income after medical spending, and reduced social connections. Two plausible explanations: first, elderly aged 75 and above are more likely to be freed from their care responsibilities for their grandchildren, financially and time-wise. In China, taking care of grandchildren before they attend college is an assumed obligation for the grandparents, especially women, in their retirement. Such an obligation can be extremely labor intensive and time consuming. Those who have multiple children sometimes have to work out a rotation system to make sure all grandchildren are cared for. Childcare 
Table 4 Regression results: predicting variables, coefficients, and $P$ values

\begin{tabular}{lcc}
\hline Predicting variable & $\begin{array}{l}\text { Standardized coefficient } \\
\text { Beta }\end{array}$ & $\begin{array}{l}\text { Significant } \\
\text { level }\end{array}$ \\
\hline Married vs. single & 0.14 & 0.03 \\
Age 75 and older & 0.11 & 0.04 \\
Physical health & 0.09 & 0.08 \\
Family relationship & 0.13 & 0.02 \\
Living with family vs. alone & 0.29 & $<0.01$ \\
Trust & 0.14 & 0.01 \\
Educational attainment & & N.S. \\
Gender & & N.S. \\
Migrants vs. locals & & N.S. \\
Big city vs none big city & & N.S. \\
Dayuan vs. Shequ & & N.S. \\
Interaction between (living with family vs. alone) and (migrants vs. & N.S. \\
locals) & & \\
\hline
\end{tabular}

N.S. not significant

responsibility is a main constraint preventing elders, especially those with limited institutional resources and external support to participate in leisure activities. Second, traditional Chinese philosophy and values might play a role here. For Chinese older adults, satisfaction and happiness represent a desirable status when they are near the end of life. The traditional philosophy of being submissive to one's fate and being at ease with life (Lu and Shih 1997) might encourage older adults to find peace with heaven, earth, and people, including their leisure lives.

Physical health has a positive impact on leisure satisfaction. Chinese seniors who are more physically healthy are more satisfied with their leisure experience. While the impacts of physical health are generally accepted in the literature, few studies have reported on physical health and leisure satisfaction of seniors in China. As the medical care system in China keeps improving along with the rapid aging of China's urban population, more seniors with good physical health will require more leisure opportunities. According to Blumenthal and Hsiao (2015) in the New England Journal of Medicine, 95\% of the Chinese population was covered by a government-subsidized comprehensive health insurance system in 2012, with a set goal of all Chinese people being covered by 2020. It will be interesting to see how physical health affects leisure in the coming years.

Family capital is instrumental in shaping leisure satisfaction of Chinese seniors. Good family relationships and living with family are important antecedents to leisure satisfaction. The family relationship measurement includes the structural, associational, consensual, affectual, functional, and normative dimensions (Bengtson and Roberts 1991). The distinctive culture of filial piety in China (Cheng and Chan 2006) emphasizes adult children's obligations to provide elder care, but the effects of the more recent one-child policy could require a couple to take care of four parents in addition to their own children. The changing dynamics of caregiving in families in Chinese cities take place in the contexts of economic and welfare reforms and continued influence of filial piety (Zhan and Montgomery 2003). The conflict between traditional cultural values and pressures of family dynamics in cities could estrange family relationships and decrease family capital. 
High family capital strongly suggests close relationships between seniors and their children and grandchildren. According to traditional Chinese values, spending time with grandchildren is the best activity the elderly can enjoy in later life (Lu and Shih 1997). Harmony with other members of the family is also highly regarded by traditional Chinese philosophy. With nuclear families becoming the new norm in Chinese cities, to live in a multigenerational family could also be a strong indicator of good relationships between the elderly and their adult children. For many Chinese seniors, their family house is where diverse leisure activities take place, and family members certainly provide crucial support for their leisure lives.

The impact of community capital is mixed in this study. When compared with human capital and family capital in a multiple regression, being a local, living in a big city, and living in a Dayuan neighborhood do not have significant impacts on leisure satisfaction of Chinese seniors. Trust, on the other hand, has a significant impact. Trust in this study measures Chinese seniors' trust toward neighbors, individuals and groups inside and outside of their communities, and individuals and groups inside and outside of their support networks. The influence of trust on leisure satisfaction is intriguing in the context of contemporary Chinese cities. Before the economic reform, Chinese cities were characterized as having dense strong-ties and thin weak-ties, caused by resource scarcity and the unique Chinese culture (Lin and $\mathrm{Si} 2010$ ). The shift from redistribution to a market economy introduced rapid and extensive household income mobility in China (Nee 1996). The economic transition and increased social mobility in China have led to changes in forms of social capital, from social networks based on strong-ties to weaker-ties (Barbalet 2014).

The two measurements of being a local and living in Dayuan are indicators of strong-ties in Chinese society. Locals who have long-established close relationships might tend to rely on strong-ties in their social networks. People living in Dayuan communities traditionally have more commonality with their neighbors, and Dayuan could be a platform for their social contacts. The size of their cities of residence matters, as smaller-size cities often suggest stronger connections among a smaller group of people. Findings in this study suggest that the traditional strong-ties-based community capital is not playing a significant role in Chinese seniors' leisure satisfaction. Trust and weak-ties-based community capital significantly affect Chinese seniors' leisure satisfaction. This reflects the broad changes in the Chinese economy and Chinese society. Seniors who have more trust in members of society likely possess more weak-ties-based social connections in their communities. Data in this study indicate the different impacts between strong-ties- and weak-ties-based community capital.

When human capital, family capital, and community capital are investigated simultaneously and compared against each other, the influence of family capital is obviously important. The significance of family echoes the cultural explanation of Chinese leisure in the literature. For example, Walker and Wang (2009) compare the meaning of leisure for Chinese and for Canadians and find that perceiving freedom is not an important distinguishing factor between leisure and non-leisure for the Chinese. Life satisfaction in later life, according to traditional Chinese culture, is dependent on spending time with family.

The importance of human capital and community capital, though, should not be neglected either. As a matter of fact, their importance will become even greater as the 
rate of population aging accelerates and adult children, become increasingly unavailable. Human capital enables seniors to overcome leisure constraints and pursue leisure satisfaction ( $\mathrm{Li}$ et al. 2017). Trust of members in the community forms the norm of reciprocity and encourages weak-ties-based social networks. As Chinese society goes through significant transformations, community capital plays an ever-bigger role in the leisure lives of Chinese seniors.

\section{Practical implications}

Important practical implications can be drawn from the findings in this study. The importance and benefits of satisfaction in their leisure lives to seniors have long been established in the literature. To improve leisure satisfaction of Chinese seniors, individuals, families, and the society at large need to work together and for each part to be effective, greater policy support will be needed.

More resources need to be invested to enhance seniors' human agency so they can invest more in themselves and improve their human capital. In other words, help them to help themselves. For instance, more community outreach programs can be done to train elders, especially those from lower socioeconomic status and with low healthy literacy, how to effectively manage the functional limitations caused by chronic illness and overcome other physical constraints preventing them from participating in meaningful and pleasurable leisure activities. As indicated in the results, which echoes findings from previous studies, better health is consistently associated with higher level of leisure satisfaction. Another gap that can be filled is the intergenerational digital divide, which may also prevent elders from fully participating in leisure activities. In today's China, the younger generation seems to live in the future-a hyper-digitalized world, whereas the older generation seems to live in the past-a world of higher level of digital illiteracy. Today's Chinese elders are not only physically but also digitally separated from their children and grandchildren and other source of social connections that are conducive to the generation of higher leisure satisfaction. We recommend the initiation of community/shequ-based programs to teach Chinese elders how to make good use of the digital devices and Internet to complement and enhance their leisure life. At the minimal, some programs need to be in place to help them navigate some of the basics of the digital world so they can stay connected with the next generations.

For instance, migrations of young workers have caused many older parents to be left behind in their hometowns. It is imperative to enact and implement social policies to enable those adult children to fulfill their filial obligations, stay connected, and provide more support to their separated parents. In addition to bridging the digital divide, we recommend the following policies: the relaxation of the Household Registration system (the Hukou system); expansion of the welfare support for migrant workers and their families in areas of housing, education, and health care in both rural villages and urban cities; more economic development initiatives in rural China to attract young workers returning to their home villages; and further government investment in developing town centers and small cities so the adult children can be close to their elderly parents while having good paying jobs.

The importance of neighborhood is accentuated among older adults as a result of declining physical mobility, mental functions and shrinking social network. Given the 
changing neighborhood ecology and family composition, urban Chinese elders in the near future would be in a greater need of community than the previous cohorts and other age groups. The society as a whole should provide more opportunities for grassroots-level civic engagement and social network building specifically focusing on how to enhance Chinese seniors' leisure satisfaction. Two concrete suggestions are as follows: (1) the construction of more public space for organized and meaningful leisure activities, and (2) accelerate the development in the field social work to help better harvest the creative and purposeful energy among the seniors.

\section{Future studies}

This empirical study has its limitations. Survey participants in this study are all city residents in China, with no participation from the vast rural areas of China. This study is based on a cross-sectional design, which does not reflect long-term changes over time. Some parts of the research hypotheses are not supported by the data in this study but warrant further investigation. Family leisure of elder migrants in the cities and the differences and similarities between elder migrants and elder local residents are two examples. Future studies could also be conducted to investigate Chinese seniors living in rural areas and their leisure satisfaction and delving deeper into the examination of how social inequality impact leisure satisfaction. Longitudinal study designs could also be applied to better understand the changes in Chinese seniors' leisure participation and leisure satisfaction.

\section{Appendix}

Measurements of two composite independent variables-family relationship and trust, as shown in the survey questionnaire

Family relationship (16 questions)

1. How would you rate your spouse's health status?
a. Very bad
b. Bad
c. Average
d. Good
e. Very good
f. Not applicable

2. In general, how would you rate your children and grandchildren's health status?
a. Very bad
b. Bad
c. Average
d. Good
e. Very good
f. Not applicable

3. Do any of your children living in the same city with you?
a. Yes
b. No

4. In general, on a weekly basis, how many times do you meet with your children and grandchildren face to face? 
5. In general, on a weekly basis, how many times do you communicate with your children and grandchildren on the phone or through the Internet?

6. In general, do you and your children and grandchildren frequently celebration important holidays and events together (Chinese New Year, Moon Festival, Dragon Boat Festival, your birthday, your children's birthday, etc.)?
a. Yes
b. No
c. Not applicable

7. Taking everything into consideration, How much do you feel that you family is willing to listen when I need to talk about my worries and problems?
a. Not at all
b. Somewhat
c. Very

8. Taking everything into consideration, how well do you and your family get along with each other?
a. Not at all
b. Somewhat
c. Very
d. Not applicable

9. Taking everything into consideration, how close do you feel to your family?
a. Not at all
b. Somewhat
c. Very
d. Not applicable

10. Regarding important decisions in the family (buying houses, marriage, etc.), how much do you feel that my family can always reach agreement?
a. Not at all
b. Somewhat
c. Very
d. Not applicable

11. Taking everything into consideration, how much do you feel that you and your family share similar values (life, consumption, politics, etc.)?
a. Not at all
b. Somewhat
c. Very
d. Not applicable

12. If you need physical support, do you think your family will provide such support?
a. Yes
b. No
c. Not applicable

13. If your family members need physical support, do you think you will provide such support?
a. Yes
b. No
c. Not applicable

14. Do you children give your financial support? 

a. Yes
b. No
c. Not applicable

15. Do you provide financial support to your children?
a. Yes
b. No
c. Not applicable

16. Generally speaking, how would you rate your children's filial piety?
a. Unfilial
b. Filial
c. Not applicable

\section{Trust}

Please evaluate the levels of trust you have toward the following groups of people.

\begin{tabular}{lllll} 
5: Highly & 4: & 3: & 2: Do not & 1: Not trust at \\
trust & Trust & Neutral & trust & all \\
\hline
\end{tabular}

\section{Neighbors}

Community administrators

Community service providers

Providers from outside of

community

Government cadre

Shop owners

Police

Medical staff

Migrant workers

Strangers in general

\section{Acknowledgements}

The authors are grateful for the hard work of their research assistants in China.

\section{Funding}

This research is partly funded by a research grant from Western Washington University. Western Washington University was not involved in the design of the study, or collection, analysis, and interpretation of data, or in writing the manuscript.

\section{Availability of data and materials}

The datasets generated during the current study are available from the corresponding author on reasonable request.

\section{Authors' contributions}

YL conceived of the study, and participated in its design and coordination and helped to draft the manuscript. $\mathrm{CH}$ conducted the statistical analysis and drafted the manuscript. Both authors read and approved the final manuscript.

\section{Competing interests}

The authors declare that they have no competing interests.

\section{Publisher's Note}

Springer Nature remains neutral with regard to jurisdictional claims in published maps and institutional affiliations.

\section{Author details}

${ }^{1}$ Hospitality and Tourism Department, State University of New York- Buffalo State, Buffalo, NY 14222, USA. ${ }^{2}$ Department of Health and Human Development, Western Washington University, Bellingham, Washington, USA. 
Received: 11 December 2018 Accepted: 5 February 2019

Published online: 27 February 2019

\section{References}

Barbalet, Jack. 2014. The structure of guanxi: resolving problems of network assurance. Theory and Society 43 (1): 51-69. Bauman, Adrian, G. Ma, Frances Cuevas, Zainal A. Omar, Temo Waqanivalu, Philayrath Phongsavan, Kieran Keke, Anjana Bhushan, and Non-communicable Disease Risk Factors Project Collaborative Group. 2010. Cross-national comparisons of socioeconomic differences in the prevalence of leisure-time and occupational physical activity, and active commuting in six Asia-Pacific countries. Journal of Epidemiology \& Community Health. https://doi.org/10.1136/jech.2008.086710.

Bengtson, Vern, and Robert E.L. Roberts. 1991. Intergenerational solidarity in aging families: an example of formal theory construction. Journal of Marriage and the Family: 856-870.

Blumenthal, David, and William Hsiao. 2015. Lessons from the East-China's rapidly evolving health care system. New England Journal of Medicine 372 (14): 1281-1285.

Bubolz, Margaret. 2001. Family as source, user, and builder of social capital. The Journal of Socio-Economics 30 (2): $129-131$.

Buchan, Nancy, and Rachel Croson. 2004. The boundaries of trust: own and others' actions in the US and China. Journal of Economic Behavior \& Organization 55 (4): 485-504.

Cheng, Sheung-Tak, and Alred C.M. Chan. 2006. Filial piety and psychological well-being in well older Chinese. The Journals of Gerontology Series B: Psychological Sciences and Social Sciences 61 (5): P262-P269.

Chick, Garry, Erwei Dong, and Svitlana larmolenko. 2014. Cultural consonance in leisure activities and self-rated health in six cities in China. World Leisure Journal 56 (2): 110-119.

Chou, Kee-Lee, Nelson W.S. Chow, and Iris Chi. 2004. Leisure participation amongst Hong Kong Chinese older adults. Ageing \& Society 24 (4): 617-629.

Coleman, Denis, and Seppo E. Iso-Ahola. 1993. Leisure and health: the role of social support and self-determination. Journal of Leisure Research 25 (2): 111.

Dong, Erwei, and Garry Chick. 2012. Leisure constraints in six Chinese cities. Leisure Sciences 34 (5): 417-435.

Findlaw.cn. 2014. Retirement age regulations. http://china.findlaw.cn/special/tuixiunianling/. Accessed 6 Apr 2014.

Flora, Cornelia. 2004. Community dynamics and social capital. In Agroecosystems analysis, ed. Diane Rickerl and Charles Francis, 93-107. Madison: American Society of Agronomy, Inc, Crop Science Society of America, Inc, and Soil Science Society of America, Inc.

Flora, Cornelia, and Jan Flora. 2002. Community dynamics and types of capital. In Challenges for rural America in the 21st century, ed. David L. Brown and Louis E. Swanson. University Park: Penn State University Press.

Floyd, Myron, Jason N. Bocarro, and Timia D. Thompson. 2008. Research on race and ethnicity in leisure studies: a review of five major journals. Journal of Leisure Research 40 (1): 1-22.

Freysinger, Valeria, Susan M. Shaw, Karla A. Henderson, and M. Deborah Bialeschki. 2013. Leisure, women, and gender. Urbana: Venture Publishing.

Gibson, Heather, and Jerome Singleton. 2012. Leisure and aging: Theory and practice. 2nd ed. Champaign: Human Kinetics.

Hayami, Yujiro. 2009. Social capital, human capital and the community mechanism: toward a conceptual framework for economists. The Journal of Development Studies 45 (1): 96-123.

Hodge, Camilla, Jason N. Bocarro, Karla A. Henderson, Ramon Zabriskie, Toby L. Parcel, and Michael A. Kanters. 2015. Family leisure: An integrative review of research from select journals. Journal of Leisure Research 47 (5): 577-600.

Huang, Bihong, Yujun Lian, and Wensu Li. 2016. How far is Chinese left-behind parents' health left behind? China Economic Review 37: 15-26.

Hurd, Amy R., and Denise M. Anderson. 2010. The park and recreation professional's handbook. Ann Arbor, MI: Sheridan Books.

International Social Survey Programme. 2007. Leisure time and sports. http://zacat.gesis.org/webview/index.jsp?object=http:// zacat.gesis.org/obj/fStudy/ZA4850. Accessed 1 Apr 2014.

Kearns, Ade. 2003. Social capital, regeneration and urban policy. Urban Renaissance 1: 37-60.

Kelly, John. 2012. Leisure. Urbana, IL: Sagamore Publishing.

Leung, Kai-Kuen, En-Chang Wu, Bee-Horng Lue, and Li-Yu Tang. 2004. The use of focus groups in evaluating quality of life components among elderly Chinese people. Quality of Life Research 13: 179-190.

Li, Monica, and Monika Stodolska. 2006. Transnationalism, leisure, and Chinese graduate students in the United States. Leisure Sciences 28 (1): 39-55.

Li, Ying, Baozhen Luo, Chenchen Huang, and Junmin Wu. 2017. Chinese seniors' leisure participation and constraints in five cities. Asian Social Science 13 (11): 24-33.

Lin, Jun, and Steven X. Si. 2010. Can guanxi be a problem? Contexts, ties, and some unfavorable consequences of social capital in China. Asia Pacific Journal of Management 27 (3): 561-581.

Liu, Jieyu. 2014. Ageing, migration and familial support in rural China. Geoforum 51: 305-312.

Lu, Luo, and Jian Bin Shih. 1997. Sources of happiness: a qualitative approach. The Journal of Social Psychology 137 (2): $181-$ 187.

Mao, Zheng-hong, and Xu-dong Zhao. 2012. The effects of social connections on self-rated physical and mental health among internal migrant and local adolescents in Shanghai, China. BMC Public Health 12 (1): 97.

Moody, Harry. 2000. Is retirement obsolete? In Aging: Concepts and controversies, ed. Harry R. Moody, 263-276. Thousand Oaks: Sage Publications.

National Bureau of Statistics of China. 2013. Report on 2012 China census: Life expectancy increased to 74.83. http://www. stats.gov.cn/tjgb/rkpcgb/qgrkpcgb/t20120921_402838652.htm. Accessed 17 June 2013.

National Population and Family Planning Committee. 2013. The Central People's Government of People's Republic of China. Release of the '2012 report on China's migrant population development' by the Department of Migrant Population Management. http://www.gov.cn/jrzg/2012-08/07/content_2199409.htm. Accessed 26 Apr 2018.

Nee, Victor. 1996. The emergence of a market society: changing mechanisms of stratification in China. American Journal of Sociology 101 (4): 908-949.

Newton, Kenneth. 2001. Trust, social capital, civil society, and democracy. International Political Science Review 22 (2): $201-214$. 
Ngai, Vong Tze. 2005. Leisure satisfaction and quality of life in Macao, China. Leisure Studies 24 (2): 195-207.

Payne, Laura, Andrew J. Mowen, and Julian Montoro-Rodriguez. 2006. The role of leisure style in maintaining the health of older adults with arthritis. Journal of Leisure Research 38 (1): 20-45.

Rosenberger, Randall, Yoav Sneh, Tim T. Phipps, and Rachel Gurvitch. 2005. A spatial analysis of linkages between health care expenditures, physical inactivity, obesity and recreation supply. Journal of Leisure Research 37 (2): 216-235.

Satariano, William, Thaddeus J. Haight, and Ira B. Tager. 2002. Living arrangements and participation in leisure-time physical activities in an older population. Journal of Aging and Health 14 (4): 427-451.

Son, Julie, Deborah L. Kerstetter, and Andrew J. Mowen. 2008. Do age and gender matter in the constraint negotiation of physically active leisure? Journal of Leisure Research 40 (2): 267-289.

Spiers, Andrew, and Gordon J. Walker. 2008. The effects of ethnicity and leisure satisfaction on happiness, peacefulness, and quality of life. Leisure Sciences 31 (1): 84-99.

Stalker, Glenn John. 2011. Leisure diversity as an indicator of cultural capital. Leisure Sciences 33 (2): 81-102.

Sun, Ying. 2000. A preliminary investigation of leisure behaviors of city elders in China: brief analysis of a small-sample questionnaire survey. City Problems 2: 29-30.

Sun, Ying, Tian Chen, and Ying Han. 2001. A preliminary study on the space and temporal distribution of leisure activities of elders living in Beijing. Geographical Research 20 (5): 537-546.

Tsai, Chiung-Tzu Lucetta. 2006. The influence of Confucianism on women's leisure in Taiwan. Leisure Studies 25 (4): 469-476.

Tsai, Eva, and Denis Coleman. 1999. Leisure constraints of Chinese immigrants: an exploratory study. Loisir et societe/Society and Leisure 22 (1): 243-264

Waite, Linda, and Maggie Gallagher. 2002. The case for marriage: why married people are happier, healthier and better off financially. New York: Broadway Books.

Walker, Gordon, and Xiye Wang. 2009. The meaning of leisure for Chinese/Canadians. Leisure Sciences 31 (1): 1-18.

World Bank. 2003. Integrated questionnaire for the measurement of social capital.http://povlibrary.worldbank.org/files/11998_ WP18-Web.pdf. Accessed 18 Jan 2014.

Yu, Zhijie, Aulikki Nissinen, Erkki Vartiainen, Guide Song, Zeyu Guo, and Huiguang Tian. 2000. Changes in cardiovascular risk factors in different socioeconomic groups: seven year trends in a Chinese urban population. Journal of Epidemiology \& Community Health 54 (9): 692-696.

Zhan, Heying, and Rhonda J.V. Montgomery. 2003. Gender and elder care in China: the influence of filial piety and structural constraints. Gender \& Society 17 (2): 209-229.

Zhang, Li. 2001. Migration and privatization of space and power in late socialist China. American Ethnologist 28 (1): 179-205.

Zhang, Zhen, and Jianxin Zhang. 2015. Belief in a just world mediates the relationship between institutional trust and life satisfaction among the elderly in China. Personality and Individual Differences 83: 164-169.

\section{Submit your manuscript to a SpringerOpen ${ }^{\circ}$ journal and benefit from:}

- Convenient online submission

- Rigorous peer review

- Open access: articles freely available online

- High visibility within the field

- Retaining the copyright to your article

Submit your next manuscript at $\boldsymbol{s p r i n g e r o p e n . c o m ~}$ 